Donald R. Hickey MD, Laurence Harrison MD, James G. Ramsay MD, J. Earl Wynands MD

\title{
Hyperkalaemic cardiac arrest follow- ing intravenous hydralazine and propranolol therapy post-embolectomy
}

A case of hyperkalaemic cardiac arrest occurring in a 50-year-old woman after bilateral femoral embolectomies is presented. The postoperative course was complicated by acute renal failure, metabolic acidosis, hypotension and low cardiac autput. The passible contribution of hydralazine and propranolot therapy to the rapid development of hyperkalaemia is discussed.

The heart is known to be extremely susceptible to the changes in membrane potential induced by hyperkalaemia. There is usually good correlation between the degree of hyperkalaemia and the presence of conduction disturbances. ${ }^{1}$ However, some circumstances may exaggerate the effects of mild hyperkalaemia and produce life-threatening cardiac dysrhythmias. The rate of rise of the serum potassium concentration is critical to the development of cardiac manifestations. ${ }^{2}$ Thus, when increased endogenous potassium loads occur (e.g., following surgery, trauma, cell destruction and rhabdomyolysis) in a setting of acute renal failure,

\section{Key words}

COMPLICATIONS: cardiac arrest, hyperkalaemia, myonephropathic syndrome; sURGERY: femoral embolectomy; CARDIOVASCULAR AGENTS: hydralazine, propranolol.

From the Department of Anaesthesia, Royal Victoria Hospital, Montreal, Quebec.

Address correspondence to: Dr. James G. Ramsay, Department of Anaesthesia, Royal Victoria Hospital, 687 Pine Avenue West, Montreal, Quebec, H3A 1 A1. life-threatening hyperkalaemia may develop very rapidly. ${ }^{3}$

\section{Case report}

A 50-year-old woman presented to the emergency department with a cold, painful right leg. Two months previously she had undergone uneventful abdominal aortic aneurysm resection and placement of an aorto-bifemoral graft. The past medical history also included mild mitral stenosis and hypertension. The patient was receiving Dyazide (hydrochlorothiazide $25 \mathrm{mg}$ plus triamterene 50 mg) 1 tablet g.d., captopril $12.5 \mathrm{mg}$ b.i.d., piroxicam $20 \mathrm{mg}$ q.d. and pentoxifylline $400 \mathrm{mg}$ b.i.d. She was a heavy smoker. On admission the heart rate was 160 and irregular, blood pressure 100/60 $\mathrm{mmHg}$ and the lungs were clear to auscultation. The right lower limb was mottled and no distal pulse was palpable. The EKG at this time showed atrial fibrillation with a ventricular response of 160 and widespread ST segment sagging ("non specific").

The patient was given divided doses of digoxin to a total of $1 \mathrm{mg} I \mathrm{~V}$, and the cardiac rhythm reverted to sinus with frequent atrial ectopic beats at 80 b.p.m. A right femoral embolectomy was performed under general anaesthesia with enflurane two hours after admission. The intraoperative course was uneventful and flow was restored to the right lower limb. Immediately postoperatively a fasciotomy of the right leg was performed under local anaesthesia due to increased tension and swelling of the involved extremity. Two hours postoperatively the patient developed acute pulmonary oedema, likely precipitated by a supraventricular tachyarrhythmnia, and suffered a respiratory 
TABLE Haemodynamic values before and after hydralazine and propranolol administration.

\begin{tabular}{|c|c|c|c|c|c|c|}
\hline & $\begin{array}{l}\text { Heart rate } \\
\left(\cdot \mathrm{min}^{-1}\right)\end{array}$ & $\begin{array}{l}\text { Bloodpressure } \\
(\mathrm{mmH} H)\end{array}$ & $\begin{array}{l}\text { Central venous } \\
\text { pressure } \\
(\mathrm{mmH} / \mathrm{g})\end{array}$ & $\begin{array}{l}\text { Pulmonary } \\
\text { capillary } \\
\text { wedge pressure } \\
\text { (mmHg) }\end{array}$ & $\begin{array}{l}\text { Systemic vascular } \\
\text { resistance } \\
\left(\text { dynes } \cdot \mathrm{sec}^{\mathrm{c}} \mathrm{cm}^{-5}\right)\end{array}$ & $\begin{array}{l}\text { Cardiac } \\
\text { output } \\
\left(L \cdot \mathrm{min}^{-1}\right)\end{array}$ \\
\hline $\begin{array}{l}\text { Before hydralazine/ } \\
\text { propranolol }\end{array}$ & 113 & $190 / 85$ & 11 & 17 & 3400 & 2.3 \\
\hline $\begin{array}{l}60 \text { minutes after } \\
\text { hydralazine } 20 \mathrm{mg} \text { and } \\
\text { propranolol } 2 \mathrm{mg} \mathrm{IV}\end{array}$ & 120 & $145 / 80$ & 11 & 17 & 2400 & 3.1 \\
\hline $\begin{array}{l}100 \text { minutes after } \\
\text { hydralazine/propranolol }\end{array}$ & 105 & $110 / 70$ & 15 & 17 & 3600 & 1.5 \\
\hline
\end{tabular}

arrest shortly after placement of a Swan Ganz catheter via the right internal jugular vein. Ventricular tachycardia then occurred but was successfully converted to sinus rhythm by D.C. cardioversion.

The postoperative course was further complicated by myoglobinuria, oliguria and hyperkalaemia (serum potassium $7.4 \mathrm{mmol} \cdot \mathrm{L}^{-1}$ ). Haemodialysis was instituted through a left subclavian catheter. During dialysis the left leg became cold and mottled with no pulse palpable distal to the femoral. Following haemodialysis the patient continued to have a metabolic acidosis ( $\mathrm{pH} 7.24)$ and a low cardiac output $\left(2.5 \mathrm{~L} \cdot \mathrm{min}^{-1}\right)$. Eighteen hours after the right femoral embolectomy the patient was returned to the operating room for a left femoral embolectomy. Under fentanyl and nitrous oxide anaesthesia an embolic clot was removed from the left femoral bifurcation, and flow was restored to the left leg with the presence of distal pulses.

After the second procedure the patient continued to require ventilatory support, remained oliguric, and the serum potassium remained elevated (5.7 $\left.\mathrm{mmol} \cdot \mathrm{L}^{-1}\right)$. The cardiac output was low $(2.3$ $L \cdot \min ^{-1}$ ) and the lower extremities appeared mottled, although distal pulses were palpable. As the haemodynamic values obtained at this time appeared to indicate low cardiac output and peripheral vasoconstriction (Table) hydralazine $20 \mathrm{mg}$ IV in incremental doses was administered in an attempt to improve cardiac output and circulation to the lower limbs. Propranolol $2 \mathrm{mg}$ IV in incremental doses was administered to control the rapid heart rhythm (sinus tachycardia with frequent atrial ectopic beats) and to prevent reflex tachycardia due to hydralazine. The Table indicates the improvement in haemodynamic variables after this therapy; however, forty minutes later there was a sudden deterioration with a fall in cardiac output (Table) and then development of wide complex bradyarrhythmia progressing to asystole. Serum potassium drawn at this time was greater than $8 \mathrm{mmol} \cdot \mathrm{L}^{-1}$. Cardiopulmonary resuscitation was instituted, and despite the use of calcium chloride, hyperventilation, dextrose 50 per cent, CZI insulin and sodium bicarbonate, the serum potassium climbed to 11.3 mmol $\cdot \mathrm{L}^{-1}$ during the resuscitation. The haemodialysis service was consulted but did not consider haemodialysis to be a possibility under the circumstances. A transvenous pacemaker was inserted but capture was not obtained and resuscitation attempts were discontinued after 90 minutes.

Post mortem examination revealed mitral stenosis, congestion of both lungs, likely due to left ventricular failure, and haemorrhagic gastritis. There was no evidence of any major thrombi or emboli. Cause of death was attributed to an arrhythmia secondary to hyperkalaemia.

\section{Discussion}

Himovici describes a myonephropathic syndrome which occurs secondary to acute arterial occlusions in 7.5 per cent of cases. ${ }^{4}$ Severe ischaemia of the skeletal muscles leads to thabdomyolysis with ensuing metabolic acidosis, hyperkalaemia and myoglobinuria with subsequent renal shutdown. The elevation in serum potassium is proportional to the duration and degree of arterial occlusion and especially the degree of muscle damage. This case vividly illustrates these metabolic complications 
following revascularization for acute arterial occlusion. Postoperatively the patient required fasciotomy of the acutely oedematous limb, then ischaemic myopathy led to myoglobinuria and oliguria. Hyperkalaemia occurred necessitating dialysis.

After the second operative procedure, hydralazine and propranolol were administered to improve the cardiac output. Hydralazine preferentially dilates the peripheral arteriolar resistance vessels leading to a reduction of systemic vascular resistance, ${ }^{5}$ and we hoped that this action, along with an improvement in cardiac output, would be beneficial. Despite what appeared to be the desired effect, however, acute hyperkalaemia developed which was unresponsive to the usual therapeutic measures. Haemodialysis which has been successfully used in the setting of hyperkalaemic cardiac arrest ${ }^{6}$ was not thought to be feasible. The sequence of events caused us to wonder if our therapy may have aggravated the hyperkalaemia.

An improvement of the circulation to postischaemic limbs might "wash out" stagnated capillary blood high in potassium. This could occur as a direct action of hydralazine on the vasculature, or as a result of an improved cardiac output. In either case increased amounts of potassium could be delivered into the circulation.

While the patient was unable to deal effectively with potassium at the renal level, another contributing factor to the sudden development of hyperkalaemia may have been the presence of propranolol. Recent studies have shown that beta adrenergic blockade impairs extra-renal disposal of an acute potassium load ${ }^{7}$ and that such extra-renal mechanisms may play an important role in circumstances such as exercise. ${ }^{8}$ Thus our therapy may have both delivered more potassium to the circulation and rendered one of the important regulatory mechanisms less effective.

As a result of the course of this patient, we must raise serious concern over management of hypertension and low cardiac output post-embolectomy, especially in the face of renal impaiment. Beta blockade may be relatively contraindicated in such circumstances, and any therapy to improve the circulation should likely be undertaken gradually, with frequent monitoring of the serum potassium level.

\section{References}

1 Ettinger PO, Regan TJ, Oldewurtel HA, Khan $M I$. Ventricular conduction delay and asystole during systemic hyperkalemia. Am J Cardiol 1974; 33: 876-86.

2 Surawicz B, Chlebus $H$, Mazzoleni A. Hemodynamic and electrocardiographic effects of hyperpotassemia. Differences in response to slow and rapid increases in concentrations of plasma potassium. Am Heart J 1967; 73: 647-64.

3 Kunis $C L$, Lowenstein J. The emergency treatment of hyperkalemia. Med Clin North Am 1981; 65: $1,165-76$.

4 Himovici $H$. Metabolic complications of acute arterial occlusions. J Cardiovasc Surg 1979; 20: 349-57.

5 Rudd P, Blaschke TF. Antihypertensive agents and the drug therapy of hypertension. In: The Pharmacological basis of Therapeutics (Ed: Gilman AG, Goodman LS, Gilman A.) New York, MacMillan Publishing 1985; 784-805.

6 Gomez-Arnau J, Criado A, Martinez MV, Aguilar $M G$, Avello $F$. Hyperkalemic cardiac arrest: prolonged heart massage and simultaneous hemodialysis. Crit Care Med 1981; 9: 556-7.

7 Epstein FH, Rosa RM. Adrenergic control of serum potassium. N Engl J Med 1983; 309: 1450-I.

8 Williams ME, Gervino EV, Rosa RM et al. Catecholamine modulation of rapid potassium shifts during exercise. N Engl J Med 1985; 312: 823-7.

\section{Résumé}

Un cas d'arrêt cardiaque dû à l'hyperkaliémie est survenu chez une patiente agée de 50 ans après des embolectomies fémorales bilatérales. L'évolution postopératoire a été compliquée d' insuffisance rénale, d'acidose métabolique, d'hypotension et de bas débit cardiaque. La contribution possible de l'hydralazine et du propranolol au développement rapide de l' hyperkaliémie est discutée. 